\title{
Preoperative Chemotherapy and Resection Margin Status in Colorectal Liver Metastasis Patients: A Propensity Score-Matched Analysis
}

\author{
LEONARDO SOLAINI, M.D., ${ }^{*}+$ ANDREA GARDINI, M.D., ${ }^{*}$ ALESSANDRO PASSARDI, M.D., $\ddagger$ \\ MARIA TERESA MIRARCHI, M.D., ${ }^{*}$ FABRIZIO D'ACAPITO, M.D., ${ }^{*}$ GIULIANO LA BARBA, M.D., ${ }^{*}$ \\ MICHELE CUCCHI, M.D.,† ANDREA CASADEI GARDINI, M.D., $\ddagger$ GIOVANNI L. FRASSINETI, M.D., \\ ALESSANDRO CUCCHETTI, M.D., ${ }^{*}$ GIORGIO ERCOLANI, M.D. ${ }^{*}$
}

From the *General and Oncologic Surgery, Morgagni-Pierantoni Hospital, AUSL Romagna, Forli, Italy; tDepartment of Medical and Surgical Sciences, University of Bologna, Bologna, Italy; and $\ddagger$ Department of Medical Oncology, Istituto Scientifico Romagnolo per lo Studio e Cura dei Tumori (IRST) IRCCS,

Meldola, Italy

In this article, we compared the early and long-term outcomes of patients with metastatic colorectal cancer treated with chemotherapy followed by resection with those of patients undergoing surgery first, focusing our analysis on resection margin status. Patients who underwent liver resection with curative intent for colorectal liver metastases from July 2001 to January 2018 were included in the analysis. Propensity score matching was used to reduce treatment allocation bias. The cohort comprised 164 patients; 117 (71.3\%) underwent liver resection first, whereas the remaining $47(28.7 \%)$ had preoperative chemotherapy. After a 1:1 ratio of propensity score matching, 47 patients per group were evaluated. A positive resection margin was found in 13 patients in the surgery-first group (25.5\%) versus $4(8.5 \%)$ in the preoperative chemotherapy group $(P=0.029)$. Postmatched logistic regression analysis showed that only preoperative chemotherapy was significantly associated with the rate of positive resection margin (odds ratio $0.24,95 \%$ confidence interval $0.07-0.81 ; P=0.022$ ). Median follow-up was 41 months (interquartile range 8-69). Cox proportional hazard regression analysis revealed that only positive resection margin was a significant negative prognostic factor (hazard ratio $2.2,95 \%$ CI 1.18-4.11; $P=0.014$ ). Within the preoperative chemotherapy group, median overall survival was 40 months in R0 patients and 10 months in $R 1$ patients $(P=0.016)$. Although preoperative chemotherapy in colorectal liver metastasis patients may affect the rate of positive resection margin, its impact on survival seems to be limited. In the present study, the most important prognostic factor was the resection margin status.

$\mathrm{R}$ ESECTION MARGIN Is a well-established prognostic factor in colorectal liver metastasis (CLM) patients. The presence of tumor cells in the resection margin decreases the five-year survival by up to 20 per cent. Conversely, disease-free margins (R0) are associated with long-term survival, with five-year survival rates $>40$ per cent. ${ }^{1,2}$ Some authors have suggested that the effect of an $\mathrm{R} 1$ resection on prognosis can be cancelled out by modern preoperative chemotherapy. ${ }^{1,3-5}$ However, there are conflicting results on the topic, with recent studies stating that preoperative

Address correspondence and reprint requests to Leonardo Solaini, M.D., General and Oncologic Surgery, Morgagni-Pierantoni Hospital, AUSL Romagna, Forlì, Italy 47100. E-mail: leonardo. solaini2@unibo.it. chemotherapy does not improve survival in marginpositive patients. ${ }^{6,7}$

In the present study, we compared the outcomes of patients who received chemotherapy followed by resection with those of patients who had surgery first. In particular, the analysis focused on the potential effect of preoperative chemotherapy on resection margin status and on the impact of the latter on survival, exploiting propensity score matching.

\section{Material and Methods}

This retrospective cohort study was designed and carried out in accordance with Strengthening the Reporting of Cohort Studies in Surgery criteria. ${ }^{8}$ All patients who had undergone liver resection with curative intent for CLMs at our center from July 1, 2001, 
to January 31,2018 , were included in the analysis. The entire cohort was divided into two groups (preoperative chemotherapy and surgery first). The primary outcome measure was the rate of positive resection margin. Secondary outcomes included overall survival (OS) and disease-free survival (DFS). Resections resulting in macroscopic tumor residue or re-resections were excluded from the analysis. Indications for preoperative chemotherapy/surgery first were confirmed by a multidisciplinary team comprising gastroenterologists, radiologists, oncologists, and surgeons.

\section{Definitions}

A positive resection margin was defined as the presence of cancer cells within $1 \mathrm{~mm}$ of the transection margin. Major hepatectomy was defined as the resection of $\geq 4$ liver segments. ${ }^{9}$ OS was defined as the

TABLE 1. Types of Preoperative Chemotherapies Used

\begin{tabular}{lc}
\multicolumn{1}{c}{ Therapy } & Number $(\%)$ \\
\hline FOLFOX + bevacizumab & $13(27.7)$ \\
FOLFOX & $13(27.7)$ \\
FOLFIRI + bevacizumab & $5(10.6)$ \\
FOLFIRI + cetuximab & $5(10.6)$ \\
FOLFIRI & $2(4.2)$ \\
capecitabine, oxaliplatin & $4(8.5)$ \\
Other & $5(10.6)$ \\
\hline
\end{tabular}

period from hepatectomy to the date of death/last follow-up. DFS was defined as the period from liver resection to the date of the first documented evidence recurrence by imaging. Postoperative complications were classified according to Dindo et al. ${ }^{10}$

\section{Statistical Analysis}

Continuous variables are presented as median and interquartile range (IQR), whereas categorical variables are shown as percentages. Distribution differences were tested using the Mann-Whitney $U$ test for continuous variables and the Fisher's exact test for categorical variables. Propensity score matching analysis was performed to minimize the potential selection bias between the two groups. Variables included in propensity score matching were age, gender, American Society of Anaesthesiologists physical status (ASA) score, number of lesions ( $>2 v s \leq 2)$, and type of primary (rectum vs colon) and synchronous liver metastasis (yes vs no). A 1:1 nearest neighbor matching algorithm without replacement was performed using a specified caliper of 0.2 of the standard deviation of the logit of the propensity score until all possible matches had been formed, as reported elsewhere. ${ }^{11}$

Kaplan-Meier survival analysis was used to determine survival variables and compared with log-rank test. Cox proportional hazards regression was performed

TABLE 2. Patient Characteristics

\begin{tabular}{|c|c|c|c|c|c|c|c|c|}
\hline \multirow[b]{2}{*}{ Variables } & \multicolumn{4}{|c|}{ All Patients } & \multicolumn{4}{|c|}{ Matched Patients } \\
\hline & $\begin{array}{c}\text { Preoperative } \\
\text { Chemotherapy } \\
(\mathrm{n}=47)\end{array}$ & $\begin{array}{l}\text { Surgery- } \\
\text { First } \\
(\mathrm{n}=117)\end{array}$ & $P$ & $\begin{array}{l}\text { Effect } \\
\text { Size }\end{array}$ & $\begin{array}{c}\text { Preoperative } \\
\text { Chemotherapy } \\
(\mathrm{n}=47)\end{array}$ & $\begin{array}{c}\text { Surgery } \\
\text { First } \\
(\mathrm{n}=47)\end{array}$ & $P$ & $\begin{array}{l}\text { Effect } \\
\text { Size }\end{array}$ \\
\hline $\begin{array}{c}\text { Age } \geq 65 \text { years } \\
\text { n }(\%)\end{array}$ & $30(63.8)$ & $67(57.3)$ & 0.55 & 0.152 & $30(63.8)$ & $29(61.7)$ & 1.000 & 0.050 \\
\hline $\mathrm{ASA}>2, \mathrm{n}(\%)$ & $14(29.8)$ & $15(12.8)$ & 0.019 & 0.584 & $14(29.8)$ & $8(17)$ & 0.223 & 0.400 \\
\hline $\begin{array}{l}\text { Rectal primary, } \\
\mathrm{n}(\%)\end{array}$ & $12(25.5)$ & $26(22.2)$ & 0.803 & 0.101 & $12(25.5)$ & $12(25.5)$ & 1.000 & 0.000 \\
\hline $\begin{array}{l}\text { Synchronous } \\
\text { metastasis, n (\%) }\end{array}$ & $30(63.8)$ & $45(38.5)$ & 0.005 & 0.572 & $30(63.8)$ & $30(63.8)$ & 1.000 & 0.000 \\
\hline K-Ras, n (\%) & & & $0.696^{*}$ & $0.156^{*}$ & & & $0.838 *$ & $0.029 *$ \\
\hline Wild type & $22(46.8)$ & $29(24.8)$ & & & $22(46.8)$ & $14(29.8)$ & & \\
\hline Mutated & $12(25.5)$ & $21(17.9)$ & & & $12(25.5)$ & $8(17)$ & & \\
\hline Not available & $13(27.6)$ & $67(57.3)$ & & & 13 (27.6) & $25(53.2)$ & & \\
\hline B-Raf, n (\%) & & & $0.121 *$ & $1.073 *$ & & & $0.305^{*}$ & $0.904 *$ \\
\hline Wild type & 19 (40.4) & $19(16.2)$ & & & 19 (40.4) & $7(14.9)$ & & \\
\hline Mutated & 7 (14.9) & $1(0.8)$ & & & 7 (14.9) & $0(0)$ & & \\
\hline Not available & $21(44.7)$ & 97 (82.9) & & & $21(44.7)$ & $40(85.1)$ & & \\
\hline $\begin{array}{l}\text { No. lesions }>2, \\
\text { n }(\%)\end{array}$ & $21(44.7)$ & $17(6)$ & 0.0001 & 0.859 & $21(44.7)$ & $17(36.2)$ & 0.065 & 0.195 \\
\hline $\begin{array}{l}\text { Tumor size } f(\mathrm{~cm}), \\
\text { median (IQR) }\end{array}$ & $3(1.7-4)$ & $3(2-4.5)$ & 0.766 & 0.000 & $3(1.7-4)$ & $3(2-4.2)$ & 0.766 & 0.000 \\
\hline
\end{tabular}

* Calculated on available data only.

$\dagger$ Diameter of the largest liver lesion.

Effect size values refer to comparison between preoperative chemotherapy and surgery first: values 0.2 indicate small differences, 0.5 indicate moderate differences, and 0.8 or more indicate considerable differences. 
to find the variables influencing OS and DFS. Followup was calculated according to Schemper and Smith. ${ }^{12}$ Logistic regression analysis was used to determine the variables affecting the rate of positive resection margin. Hazard ratios (HR), odds ratios (OR), and $95 \%$ confidence intervals $(95 \% \mathrm{CI})$ were calculated when required. Analyses were performed using MedCalc Statistical Software version 15.8 (MedCalc Software bvba, Ostend, Belgium; https:// www.medcalc.org; 2015).

\section{Results}

The cohort comprised 164 patients; 117 (71.3\%) underwent liver resection first, whereas the remaining $47(28.7 \%)$ had preoperative chemotherapy. The type of chemotherapy used is reported in Table 1 . The rate of patients with ASA score $>2$, synchronous metastasis, and with $>2$ liver lesions differed significantly between the two groups (Table 2). After a 1:1 ratio of propensity score matching, 47 patients per group were included for analysis. No significant differences in baseline characteristics were found between two groups in the postmatch analysis (Table 2 and 3 ).

\section{Postmatched Analysis}

In the preoperative chemotherapy group, 33 cases $(70.2 \%)$ were judged technically resectable before medical treatment. A positive resection margin was found in 13 patients in the surgery-first group (25.5\%) compared with four $(8.5 \%)$ in the preoperative chemotherapy group $(P=0.029)$. Logistic regression analysis performed on 94 patients showed that only preoperative chemotherapy was significantly associated with the rate of positive resection margin (OR $0.26,95 \%$ CI $0.08-0.88) ; P=0.031$ ) (Table 4).

\section{T4}

\section{Survival Analysis}

Median follow-up was 41 months (IQR 8-69). Median OS for the entire cohort $(\mathrm{n}=94)$ was 43 months with a one-, three- and five-year survival of 78.2 per cent, 61.2 per cent, and 31.4 per cent, respectively. Median DFS was 17 months with a one-, three-, and five-year survival of 57.2 per cent, 29.0 per cent, and 16.9 per cent, respectively. Median OS was 46 months in the surgery-first group versus 39 months in the preoperative chemotherapy group $(P=0.929)$ (Fig. F1 1). Cox proportional hazard regression showed that only positive resection margin was significantly associated with poor survival (HR 2.2, 95\% CI 1.18-4.11; $P=0.014$ ) (Table 5) (Fig. 2). In the preoperative T5 F2 chemotherapy group, median OS was 40 months in R0 patients and 10 months in $\mathrm{R} 1$ patients $(P=0.016)$ (Fig. 3). Hepatic recurrence was recorded in 10 cases F3 in the preoperative chemotherapy group and in 12 cases in the surgery-first group $(P=0.802)$. No significant factors influencing DFS were found (Table 5).

\section{Discussion}

Preoperative chemotherapy was associated with a higher rate of radical resection in our cohort. Two studies reported no differences in R0 rates between groups of patients submitted or not to preoperative chemotherapy. ${ }^{3,7}$ In 2014, these outcomes were confirmed in a meta-analysis of randomized trials ${ }^{13}$

TABle 3. Matched Patients Operative and Postoperative Variables

\begin{tabular}{lcrc}
\multicolumn{1}{c}{ Variables } & Preoperative Chemotherapy $(\mathrm{n}=47)$ & Surgery First $(\mathrm{n}=47)$ & $P$ \\
\hline Major liver resection, $\mathrm{n}(\%)$ & $7(14.9)$ & $9(19.1)$ & 0.784 \\
Intraoperative transfusion, $\mathrm{n}(\%)$ & $3(6.4)$ & $3(6.4)$ & 1.000 \\
Postoperative complications, $\mathrm{n}(\%)$ & $19(40.4)$ & $14(29.8)$ & 0.387 \\
Clavien-Dindo > & $2(4.2)$ & $5(10.6)$ & 0.432 \\
Hospital stay (days), median (IQR) & $9(7-12)$ & $9(8-13)$ & 0.229 \\
\hline
\end{tabular}

TABLE 4. OR for Rl in the Matched Cohort

\begin{tabular}{lcc}
\hline \multicolumn{1}{c}{ Variables } & OR $(95 \%$ CI $)$ & $P$ \\
\hline ASA $>2$ & $0.81(0.29-2.19)$ & 0.671 \\
Age $>$ 65 female & $1.01(0.96-1.07)$ & 0.564 \\
Gender -femary & $1.09(0.34-3.52)$ & 0.879 \\
Rectal primary & $0.91(0.26-3.17)$ & 0.891 \\
No. of hepatic lesions $>2$ & $1.16(0.39-3.47)$ & 0.782 \\
Tumor diameter* & $1.04(0.88-1.21)$ & 0.658 \\
Synchronous metastases & $0.99(0.32-3.03)$ & 0.999 \\
Preoperative chemotherapy & $0.26(0.08-0.88)$ & 0.031 \\
\hline
\end{tabular}

* Analyzed as continuous variable. 


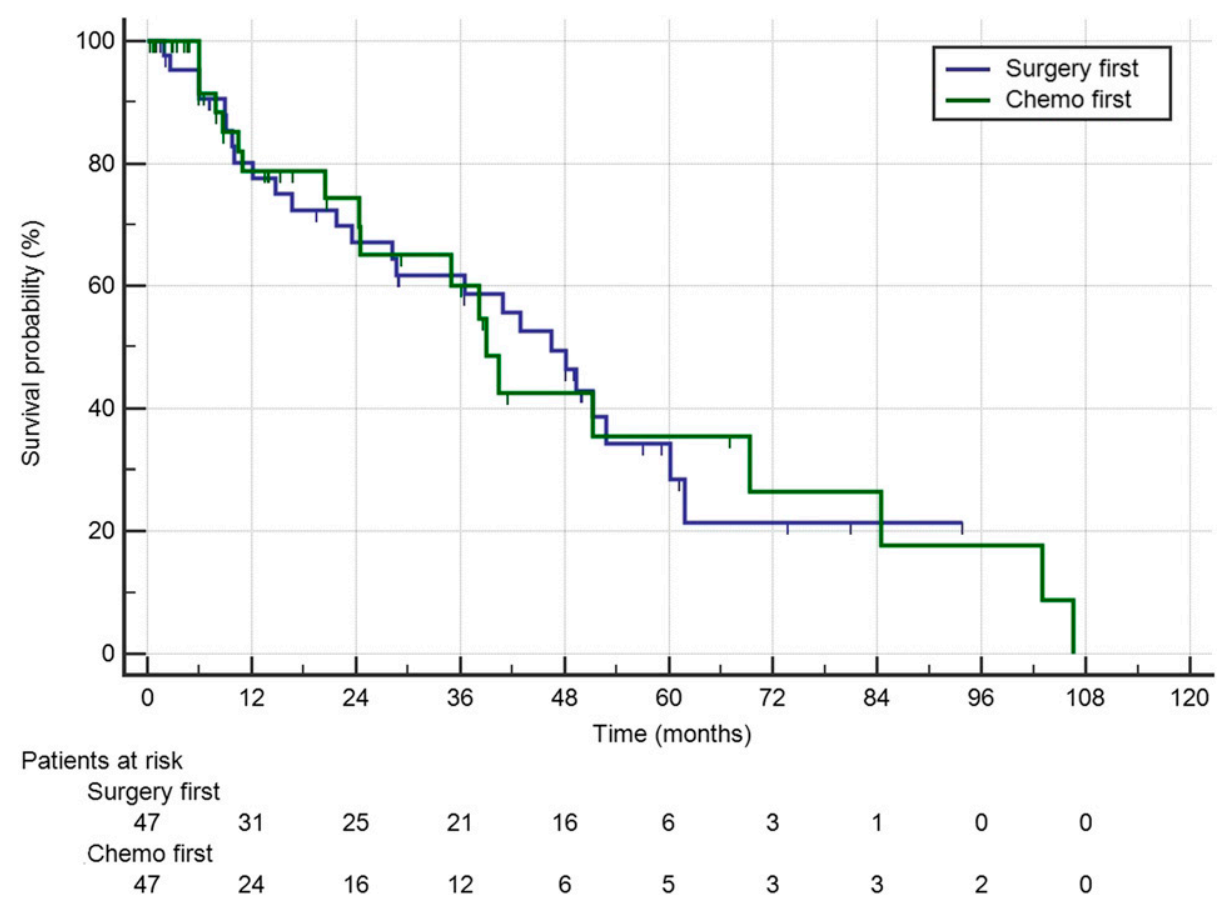

FIG. 1. Kaplan-Meier survival curves comparing the two groups in the matched cohort.

TABLE 5. Cox Regression Analysis in the Matched Cohort

\begin{tabular}{|c|c|c|c|c|}
\hline \multirow[b]{2}{*}{ Variables } & \multicolumn{2}{|c|}{ OS } & \multicolumn{2}{|c|}{ DFS } \\
\hline & $\mathrm{HR}(95 \% \mathrm{CI})$ & $P$ & HR $(95 \%$ CI $)$ & $P$ \\
\hline ASA > 2 & $1.41(0.68-2.93)$ & 0.353 & $0.81(0.45-1.45)$ & 0.485 \\
\hline Age $>65$ & $0.98(0.95-2.95)$ & 0.213 & $0.58(0.34-0.96)$ & 0.046 \\
\hline Gender-female & $1.11(0.57-2.14)$ & 0.213 & $1.69(0.95-3.00)$ & 0.076 \\
\hline Rectal primary & $0.69(0.34-1.41)$ & 0.312 & $0.67(0.36-1.28)$ & 0.229 \\
\hline No. of hepatic lesions $>2$ & $1.31(0.61-2.09)$ & 0.694 & $1.14(0.67-1.96)$ & 0.612 \\
\hline Tumor diameter* & $1.03(0.9-1.18)$ & 0.666 & $0.95(0.84-1.08)$ & 0.446 \\
\hline Synchronous metastases & $1.27(0.67-2.41)$ & 0.465 & $0.96(0.56-1.67)$ & 0.895 \\
\hline Preoperative chemotherapy & $0.97(0.52-1.81)$ & 0.929 & $1.1(0.65-1.87)$ & 0.724 \\
\hline Major resection & $2.09(0.86-5.06)$ & 0.103 & $0.79(0.31-1.99)$ & 0.628 \\
\hline Transfusions & $0.91(0.34-2.37)$ & 0.839 & $0.91(0.33-2.53)$ & 0.918 \\
\hline Postoperative complications & $1.58(0.85-2.95)$ & 0.151 & $1.71(0.99-2.95)$ & 0.058 \\
\hline Positive resection margin (R1) & $2.2(1.18-4.11)$ & 0.014 & $1.12(0.55-2.31)$ & 0.743 \\
\hline Adjuvant chemotherapy & $0.81(0.37-1.73)$ & 0.586 & $1.53(0.82-2.85)$ & 0.183 \\
\hline
\end{tabular}

* Analyzed as continuous variable.

comparing outcomes of patients who underwent preoperative chemotherapy with those of patients receiving surgery alone: the pooled results of $\mathrm{R} 0$ resections in the two groups were 86.5 per cent in the neoadjuvant chemotherapy group and 84 per cent in the surgeryalone group, although one of the included trials ${ }^{14}$ had a significantly higher rate of $\mathrm{R} 1$ resections in the surgery-alone group. A more recent meta-analysis by Cui et al. ${ }^{15}$ found that neoadjuvant chemotherapy associated with bevacizumab- and irinotecan-based treatment plus targeted therapy significantly increased $\mathrm{R} 0$ resection rates when compared with neoadjuvant chemotherapy alone.
Our results seem to confirm Cui et al.'s finding: in fact, $23(48.9 \%)$ patients received preoperative folinic acid, 5-fluorouracil, oxaliplatin/folinic acid, 5-fluorouracil, and oxaliplatin (FOLFOX/FOLFIRI) plus targeted therapy, whereas $18(78.3 \%)$ underwent treatment with bevacizumab. Preoperative chemotherapy did not affect OS in the cohort, and the significant difference between the R0 and R1 groups was also maintained in the subgroup receiving preoperative chemotherapy. These findings are in line with those of other authors. ${ }^{6,7}$ Pandanaboyana et al., ${ }^{7}$ analyzing 1255 patients, found that neoadjuvant chemotherapy in those with positive resection margins did not have an 


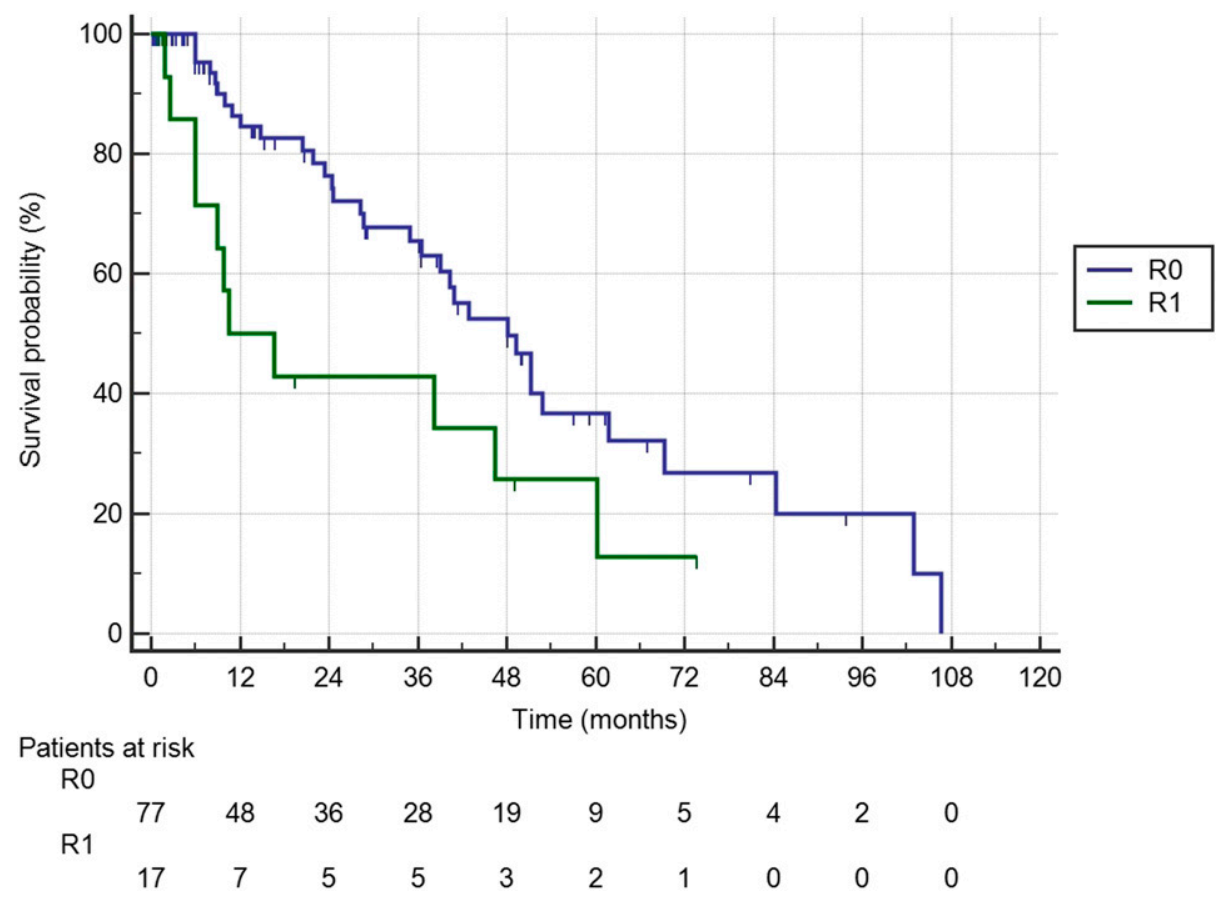

FIG. 2. Kaplan-Meier survival curves comparing R0 and R1 patients in the matched cohort.

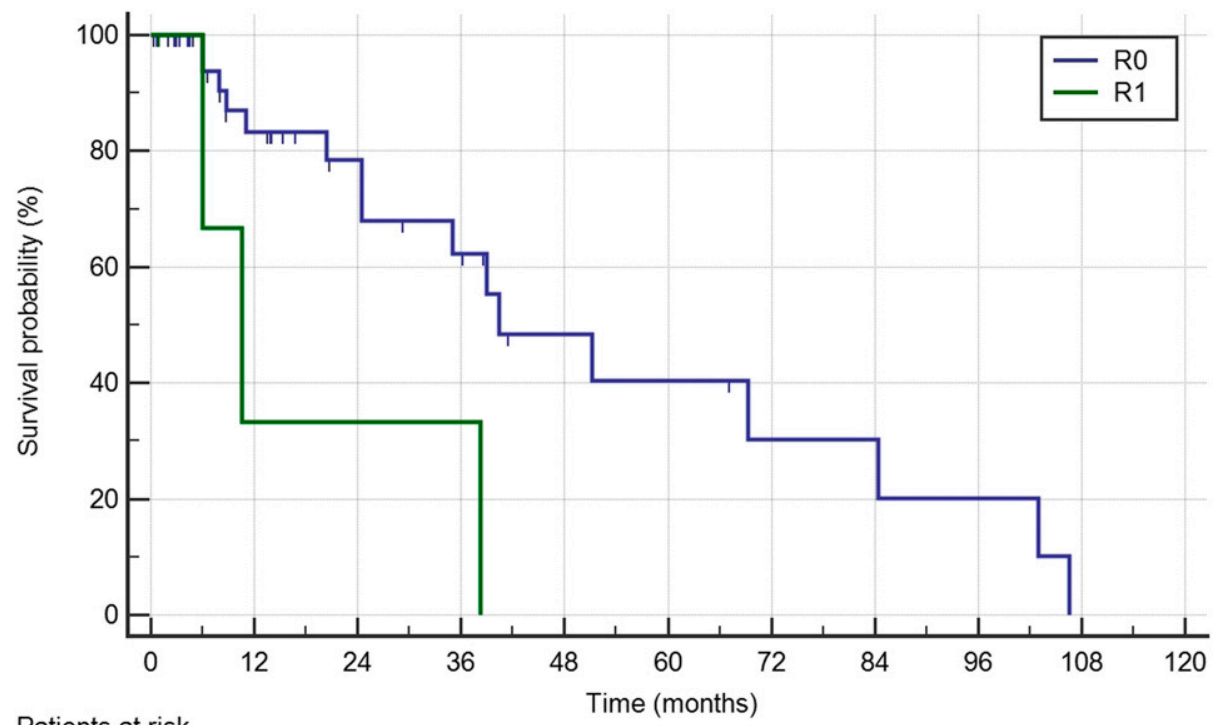

Patients at risk

\begin{tabular}{|c|c|c|c|c|c|c|c|c|c|}
\hline 43 & 23 & 15 & 11 & 6 & 5 & 3 & 3 & 2 & 0 \\
\hline $\mathrm{R} 1$ & & & & & & & & & \\
\hline 4 & 1 & 1 & 1 & 0 & 0 & 0 & 0 & 0 & 0 \\
\hline
\end{tabular}

FIG. 3. Kaplan-Meier survival curves comparing R0 and R1 patients who had preoperative chemotherapy in the matched cohort.

impact on recurrence or on the need for further liver surgery. However, there several authors have reported that preoperative chemotherapy guarantees the same survival for both R0 patients and those who have positive resection margins. ${ }^{1,3-5}$ However, only four of our patients who had preoperative chemotherapy were
$\mathrm{R} 1$, indicating the need to confirm our findings in larger cohorts.

In the present study, the use of neoadjuvant chemotherapy did not have a significant impact on surgical safety, as reported by others. ${ }^{16,17}$ Even the patients who underwent preoperative bevacizumab, which has been 
reported as a potential risk factor for increased postoperative morbidity, ${ }^{18}, 19$ showed a similar rate of postoperative complications to that of the general population.

Our study has a number of limitations because of the retrospective nature of the analysis. First, information on some parameters such as b-raf ${ }^{20}$ and inflammatory prognostic scores, ${ }^{21,22}$ which are acknowledged as significant prognostic factors, could not be retrieved, and this may have influenced the survival analysis. Second, the chemotherapy drug schemes used were heterogeneous in the preoperative chemotherapy group and, thus, the specific effect of one treatment compared with another could not be determined. Conversely, the main strength of this article lies in its use of propensity score matching to reduce the selection bias and increase our understanding of the real impact of preoperative chemotherapy in two comparable groups.

In conclusion, although preoperative chemotherapy in CLM patients may affect the rate of positive resection margin, its impact on survival seems limited. In the present analysis, the most important prognostic factor proved to be resection margin status.

\section{REFERENCES}

1. Cucchetti A, Ercolani G, Cescon M, et al. Impact of subcentimeter margin on outcome after hepatic resection for colorectal metastases: a meta-regression approach. Surgery 2012;151:691-9.

2. Dhir M, Lyden ER, Wang A, et al. Influence of margins on overall survival after hepatic resection for colorectal metastasis: a meta-analysis. Ann Surg 2011;254:234-42.

3. Ayez N, Lalmahomed ZS, Eggermont AM, et al. Outcome of microscopic incomplete resection (R1) of colorectal liver metastases in the era of neoadjuvant chemotherapy. Ann Surg Oncol 2012;19:1618-27.

4. Hosokawa I, Allard MA, Gelli M, et al. Long-term survival benefit and potential for cure after $\mathrm{R} 1$ resection for colorectal liver metastases. Ann Surg Oncol 2016;23:1897-905.

5. Laurent C, Adam JP, Denost Q, et al. Significance of $\mathrm{R} 1$ resection for advanced colorectal liver metastases in the era of modern effective chemotherapy. World J Surg 2016;40: 1191-9.

6. Makowiec F, Bronsert P, Klock A, et al. Prognostic influence of hepatic margin after resection of colorectal liver metastasis: role of modern preoperative chemotherapy. Int J Colorectal Dis 2018; 33:71-8.

7. Pandanaboyana S, White A, Pathak S, et al. Impact of margin status and neoadjuvant chemotherapy on survival, recurrence after liver resection for colorectal liver metastasis. Ann Surg Oncol 2015;22:173-9.
8. Agha RA, Borrelli MR, Vella-Baldacchino M, et al. The STROCSS statement: strengthening the reporting of cohort studies in surgery. Int J Surg 2017;46:198-202.

9. Reddy SK, Barbas AS, Turley RS, et al. A standard definition of major hepatectomy: resection of four or more liver segments. HPB (Oxford) 2011;13(7):494-502.

10. Dindo D, Demartines N, Clavien PA. Classification of surgical complications: a new proposal with evaluation in a cohort of 6336 patients and results of a survey. Ann Surg 2004;240:205-13.

11. Austin PC. Optimal caliper widths for propensity-score matching when estimating differences in means and differences in proportions in observational studies. Pharm Stat 2011;10:150-61.

12. Schemper M, Smith TL. A note on quantifying follow-up in studies of failure time. Control Clin Trials 1996;17:343-6.

13. Huang L, Li TJ, Zhang JW, et al. Neoadjuvant chemotherapy followed by surgery versus surgery alone for colorectal cancer: meta-analysis of randomized controlled trials. Medicine (Baltimore) 2014;93:e231.

14. Foxtrot Collaborative Group. Feasibility of preoperative chemotherapy for locally advanced, operable colon cancer: the pilot phase of a randomised controlled trial. Lancet Oncol 2012;13: 1152-60.

15. Cui CH, Huang SX, Qi J, et al. Neoadjuvant chemotherapy (NCT) plus targeted agents versus NCT alone in colorectal liver metastases patients: a systematic review and meta-analysis. Oncotarget 2015;6:44005-18.

16. Cucchetti A, Ercolani G, Cescon M, et al. Safety of hepatic resection for colorectal metastases in the era of neo-adjuvant chemotherapy. Langenbecks Arch Surg 2012;397:397-405.

17. Wolf PS, Park JO, Bao F, et al. Preoperative chemotherapy and the risk of hepatotoxicity and morbidity after liver resection for metastatic colorectal cancer: a single institution experience. J Am Coll Surg 2013;216:41-9.

18. Ganapathi AM, Westmoreland T, Tyler D, et al. Bevacizumab-associated fistula formation in postoperative colorectal cancer patients. J Am Coll Surg 2012;214:582-90.

19. Nasti G, Piccirillo MC, Izzo F, et al. Neoadjuvant FOLFIRI+bevacizumab in patients with resectable liver metastases from colorectal cancer: a phase 2 trial. Br J Cancer 2013;108: $1566-70$.

20. Margonis GA, Buettner S, Andreatos N, et al. Prognostic factors change over time after hepatectomy for colorectal liver metastases: a multi-institutional, international analysis of 1099 patients. Ann Surg 2018. doi: 10.1097/SLA.0000000000002664.

21. Kostner AH, Kersten C, Lowenmark T, et al. The prognostic role of systemic inflammation in patients undergoing resection of colorectal liver metastases: C-reactive protein (CRP) is a strong negative prognostic biomarker. J Surg Oncol 2016;114:895-9.

22. Solaini L, Atmaja BT, Arumugam P, et al. The role of perioperative inflammatory-based prognostic systems in patients with colorectal liver metastases undergoing surgery. A cohort study. Int J Surg 2016;36:8-12. 